\title{
An Investigation on the Adaptive Modal Combination Procedure for Seismic Evaluation of Buildings Considered Soil Structure Interaction
}

\author{
Hong-An Nguyen ${ }^{1}$, Chatpan Chintanapakdee ${ }^{2}$ \\ ${ }^{1}$ Faculty of Civil Engineering, Ho Chi Minh City University of Technology, Vietnam \\ ${ }^{2}$ Faculty of Engineering, Chulalongkorn University, Bangkok, Thailand, \\ *Corresponding author: annguyenbk@gmail.com
}

\begin{abstract}
Nonlinear response history analysis (NL-RHA) is a powerful tool for seismic analysis of structures. The seismic performance of structures can be estimated accurately due to a set of ground motions. However, NL-RHA is an onerous task to estimate seismic demands due to its complexity for practical design applications. Therefore, nonlinear static procedures (NSPs), which are rooted in structural dynamic theory, are developed as an alternative to rigorous NL-RHA. NSPs are now widely used in engineering practice to evaluate seismic responses of structure in the inelastic range. The main objective of this study is to assess the bias and accuracy of the adaptive modal combination (AMC) procedure, which is modified from the modal pushover analysis (MPA) procedure, for seismic evaluation of buildings. Three-, 9-, 18-storey buildings were analyzed due to two sets of strong ground motions having $2 \%$ and $10 \%$ probability of being exceeded in 50 years. The influence of soil-structure interaction in the analysis was also considered by using Beam-on-Nonlinear-Winkler-Foundation modeling. The assessment is based on comparing seismic displacement demands such as target roof displacements, peak floor displacements and inter-storey drifts. The AMC estimates are compared to results from nonlinear response history analysis (NL-RHA) and results from AMC procedure considered only first mode (AMC- ${ }^{\text {st }}$ mode). The obtained results show that the AMC procedure provides reasonably accurate results in estimating seismic demands of studied buildings.
\end{abstract}

Keywords - Nonlinear static procedure, adaptive modal combination procedure, seismic demand, modal pushover analysis, soil structure interaction.

\section{INTRODUCTION}

A though nonlinear response history analysis (NL-

RHA) is considered to be the most rigorous method to determine responses of a structure due to a strong earthquake excitation, it can only be undertaken by highly qualified engineers and may be too timeconsuming for typical structural design and evaluation projects. The nonlinear static procedure, or pushover analysis, thus became a popular method to estimate building responses considering inelastic behavior, although the results are not as accurate as those from NL-RHA. Nonlinear static procedures (NSPs) using the lateral force distributions recommended in ATC-40, FEMA-356 and FEMA-440 documents are now widely used in engineering practice [1][2]. These NSPs based on invariant load patterns provide accurate seismic demand estimates only for low- and medium-rise moment-frame buildings where contributions of higher 'modes' response are not significant and inadequate to predict inelastic seismic demands in buildings when the higher 'modes' contribute to the response. To overcome these limitations, a multi-mode pushover procedure called modal pushover analysis (MPA) was proposed by Chopra and Goel (2002) [4] to include contributions of higher 'modes'. The MPA procedure has been demonstrated to increase accuracy of seismic demand estimation in taller moment-frame buildings compared to conventional pushover analysis (Chopra and Goel, 2002; Chintanapakdee and Chopra, 2003; Chopra and Chintanapakdee, 2004; and Chopra et al., 2004; and Nguyen et al., 2010) [4-8].

One of critical tasks of nonlinear static procedures is to predict the target displacement of inelastic multi-degreeof-freedom structures due to a ground motion. Several approaches were proposed to estimate the target displacement by using an equivalent single-degree-offreedom (SDF) system. The methods described in the ATC-40 and FEMA-356 guidelines are now commonly used in practice. According to the nonlinear static procedure described in ATC-40 and FEMA-356 documents, seismic demands are computed by nonlinear static analysis of a structure subjected to monotonically increasing lateral loads representing inertia forces in an earthquake (pushover analysis) with a specified, usually invariant height-wise distribution until a pre-determined target displacement is reached. The target displacement of these procedures is estimated from the deformation $D$ of an equivalent inelastic SDF system which is derived from relationship between base shear force and roof displacement known as the pushover curve.

The ATC-40 presents an approach, called Capacity Spectrum Method (CSM), to estimate seismic response of inelastic SDF systems where the deformation $D$ of an inelastic SDF system is determined by an iterative method which requires analysis of a sequence of equivalent linear systems with successively updated values of period and damping ratio. This method is 
typically implemented graphically. However, the accuracy and convergence of the ATC-40 iterative procedure can be considerable (Chopra and Goel, 2000) [9]. The ATC-40 tends to underestimate the deformation over a wide range of periods. Unlike the ATC-40 Capacity Spectrum Method, FEMA-356 presents an alternative approach, known as Displacement Coefficient Method (DCM), in which the deformation $D$ of an inelastic SDF system is estimated by multiplying the deformation of the corresponding linear system. The limitations on accuracy of ATC-40 Capacity Spectrum Method such as lack of convergence or large errors in some case (Chopra and Goel, 2000) [9], and the lack on research results of coefficient $C_{1}$ of FEMA-356 Displacement Coefficient Method are specified and rectified in FEMA-440 report (ATC, 2005). Then, an investigation on accuracy of improved nonlinear static procedures in FEMA-440 was carried out by Akkar and Metin, (2007) [10]. It was found that both of these improved procedures provide fairly good deformation demand estimations.

To overcome the limitation of previous mentioned methods, several improved methods were proposed and investigated. An improved Capacity Demand Diagram (CDD) method, which is originally developed by Freeman et al. (1975) and Freeman (1978) [11,12], based on inelastic design spectrum for estimating seismic deformation of inelastic structures using SDF systems was developed and illustrated by Chopra and Goel, (1999) [13]. Subsequently, Chopra et al. (2001) [14], and Chopra and Goel, (2002) [4] suggested that the contribution of the $n$th vibration mode to the target roof displacement of an inelastic MDF system in MPA procedure is calculated from the peak value of deformation of an equivalent inelastic SDF system of $n$th 'mode', determined rigorously by nonlinear response history analysis by solving the uncoupled modal response history analysis (UMRHA) governing equation for the $n$th 'mode'. For planar analysis of symmetricplan building, the peak modal responses, each determined by pushover analysis for modal force distribution and dynamic analysis of the $n$th 'mode' inelastic SDF system, may be combined using an appropriate modal combination rule such as the squareroot-of-sum-of-squares (SRSS) rule to obtain a MPA estimate of the total roof displacement.

Then, an investigation on accuracy of single-degree-offreedom estimate of displacement for pushover analysis of buildings was carried out by Chopra et al. (2003) [15]. The statistics presented show that the roof displacement of a multi-story building can be determined from the deformation of the SDF system. The estimation considering first 'mode' SDF system overestimates the median roof displacement for systems subjected to large ductility demand $\mu$, but underestimates for small $\mu$. The bias and dispersion of this method tend to increase for longer period system for every value of $\mu$ and increasing when $P$ - $\Delta$ effects are included due to gravity loads. On the other hand, considering the contribution of higher 'modes' of MPA procedure helps reduce the dispersion in the roof displacement, but it increases slightly the overestimate of roof displacement of buildings responding far into the inelastic range (Chopra et al., 2003) [15].

An alternative pushover method is the adaptive pushover procedure in which the load pattern distributions are redefined. The loading pattern is determined by modal combination rules (e.g. SRSS of modal loads) at each stage of the response during which the dynamic characteristics of the structure change, usually at each step when a new plastic hinge forms in inelastic range (Fajfar and Fischinger, 1988; Bracci et al., 1997; and Gupta and Kunnath, 2000) [16-18]. In this procedure, equivalent seismic loads are calculated at each pushover step using the immediate 'mode' shape. Recently, a new adaptive pushover method, called Adaptive Modal Combination (AMC) procedure, has been developed by Kalkan and Kunnath, (2006) [19] where a set of adaptive mode-shape based inertia force patterns is applied to the structure.

When a structure is subjected to inertial loading due to earthquake ground motion, the foundation may undergo sliding, settling and rocking movements. Therefore, the soil structure interaction (SSI) has a significant effect on the vibrational properties and dynamic responses of the structural system. The calculation of structures subjected to earthquake loads is often overlooked the influence of the SSI and is often based on the assumption that the foundation is a solid block. This assumption is true if the structural system is placed on good foundation. However, there will be significant differences if the ground is weak. If the capacity of the foundation is mobilized, the soil-foundation interface will dissipate significant amounts of vibrational energy, resulting in a reduction in structural force demand [20]. Due to the above effects, it is necessary to mention the role of soil foundation in the SSI model when analyzing earthquake resistant works.

The problem of interaction between soil and structure has been paid much attention in recent years by the accuracy and reasonableness of the model. It can simulate the simultaneous operation of the structure and soil during subjected to earthquake loads. As a result, the models which have calculation to the impact of SSI have working very close to the fact. In many cases, the soil is assumed to be elastic material. This assumption does not accurately reflect the properties of the soil in fact. Presently, with the appearance of soil characterization models and the development of analytical methods have allowed simulations of soil - structure behavior under the effect of earthquake ground motion.

The main objective of this study is to assess the bias and accuracy of the adaptive modal combination procedure, which is adapted from MPA procedure, for seismic evaluation of buildings. Three-, 9-, 18-storey buildings were analyzed due to two sets of strong ground motions having $2 \%$ and $10 \%$ probability of being exceeded in 50 years. The influence of soil-structure interaction in the analysis was also considered by using Beam-on-Nonlinear-Winkler-Foundation modeling [20]. The assessment is based on comparing seismic displacement demands such as target roof displacements, peak floor displacements and inter-storey drifts. The peak modal responses are combined by using SquareRoot-of-Sum-of-Squares (SRSS rules. The AMC 

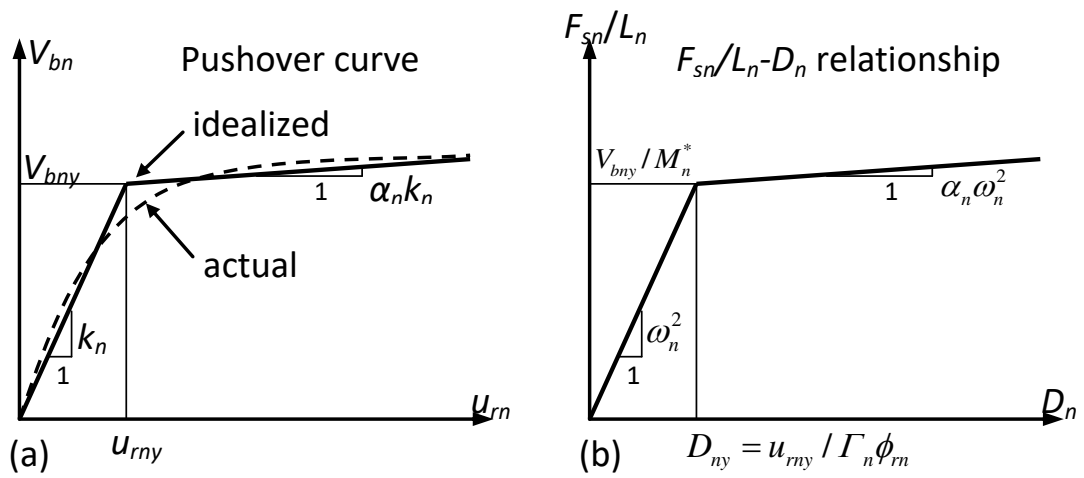

Figure 1. (a) Pushover curve and (b) Force and deformation relationship of SDF system.

estimates are compared to results from nonlinear response history analysis (NL-RHA) and results from AMC procedure considered only first mode (AMC- $1^{\text {st }}$ mode).

\section{METHOD}

The Adaptive Modal Combination (AMC), which has been proposed by Kalkan and Kunnath (2006) [19], is an extension of Modal Pushover Analysis procedure where a set of adaptive mode-shape based inertia force patterns is applied to the structure. A step-by-step summary of the AMC procedure used in this study to estimate the seismic demands for building is presented as a sequence of steps:

(1) Compute the natural frequencies, $\omega_{n}$, and mode shape vectors of the building, $\phi_{n}$, for each step of pushover analysis.

(2) For the $n$ th-'mode', develop the base-shear-roofdisplacement $\left(V_{b n}-u_{r n}\right)$ pushover curve by nonlinear static analysis of the building using the force distribution $\mathbf{s}_{n}^{*}=\mathbf{m} \phi_{n}$ where $\mathbf{m}$ is the mass matrix and $\phi_{n}$ is adaptive mode shape at each step of pushover analysis.

(3) Idealize the pushover curve as a bilinear curve (Figure 1a).

(4) Convert the idealized pushover curve to the forcedeformation $\left(F_{s n} / L_{n}-D_{n}\right)$ relation of the $n$ th-'mode' inelastic SDF system and determine the elastic modal frequency $\omega_{n}$, and yield deformation $D_{n y}$. The $n$ th'mode' inelastic SDF system is defined by the forcedeformation curve of Figure $1 \mathrm{~b}$ (with post-yield stiffness ratio $\alpha_{n}$ ) and damping ratio $\zeta_{n}$ specified for the $n$th 'mode'. Where $M_{n}^{*}=\Gamma_{n} L_{n}$ is the effective modal mass, $L_{n}=\phi_{n}^{T} \mathbf{m} \mathbf{\imath}, \Gamma_{n}=\frac{\phi_{n}^{T} \mathbf{m} \mathbf{\imath}}{\phi_{n}^{T} \mathbf{m} \phi_{n}}$, and each element of the influence vector $\mathbf{l}$ is equal to unity.

(5) Compute the peak deformation, $D_{n} \equiv \max _{\forall t}\left|D_{n}(t)\right|$, of the $n$ th-'mode' inelastic SDF system with forcedeformation relation of Fig. $1 \mathrm{~b}$ due to ground excitation $\ddot{u}_{g}(t)$ by solving:
$\ddot{D}_{n}+2 \zeta_{n} \omega_{n} \dot{D}_{n}+\frac{F_{s n}\left(D_{n}, \dot{D}_{n}\right)}{L_{n}}=-\ddot{u}_{g}(t)$

(6) Calculate the peak roof displacement $u_{r n o}$ associated with the $n$ th-'mode' inelastic SDF system from

$u_{r n o}=\Gamma_{n} \phi_{r n} D_{n}$

(7) Extract other desired responses, $r_{n o}$, from the pushover database when roof displacement equal to $u_{r n o}$. (8) Repeat Steps 2-7 for as many 'modes' as required for sufficient accuracy; usually the first two or three 'modes' will suffice for buildings shorter than 10 stories.

(9) Determine the total response $r_{M P A}$ by combining the peak 'modal' responses using appropriate modal combination rule, e.g., Square-Root-of-Sum-of-Squares (SRSS) as shown by Equation (3) or Complete Quadratic Combination (CQC) rule:

$r_{M P A}=\sqrt{\sum_{n=1}^{j} r_{n o}^{2}}$

where $j$ is the number of 'modes' included.

\section{STRUTURAL SYSTEMS}

Analyses of 3-, 9-, and 18-story buildings are presented to evaluate the bias and accuracy of AMC procedure. These building systems are model cases studied by Goel and Chopra (1997) [21]. They represent the lateral load resisting systems of buildings with plan symmetric about two orthogonal directions and subjected to earthquake ground motion along an axis of symmetry. All the generic frames used in this study are designed according to strong-column weak beam concept. This results in beam-sway type of plastic mechanism and ensures optimal performance of the structure under extreme seismic loading thereby ensuring premature-failure of the structure due to formation of story mechanism. In other words, the beams and columns are designed such that inelastic deformations occur only at the beam ends and the base of the ground floor columns. All other columns are assumed to remain elastic.

Inelasticity in the generic frames being considered is modeled by concentrated plastic hinges. The two ends of the beams of all the stories and the base of the column in the ground floor are each assigned a concentrated rotational plastic hinge. The moment-rotation 
relationship of the plastic hinges is represented by symmetric, non-degrading rigid-plastic model with $3 \%$ strain hardening. A schematic diagram of the momentrotation relationship of a typical plastic hinge is shown in Figure 2.

The frames considered are a set of generic one-bay frames of three different heights: 3, 9, and 18 stories. Each story has a height equal to 144 inches and the bay length of each frame is equal to 288 inches. In all the 3 generic frames considered in this study, mass equal to 200 kips is assigned to each story. The mass at each storey is considered to be lumped mass. The elevation view of all systems is shown in Figure 3. Analytical models were created to analyze these buildings whose details can be found in Goel and Chopra (1997) [21]. Rayleigh damping model was used with $5 \%$ critical damping ratios for the first two modes, according to common practice for code designed steel structures [22]. Nonlinear static and dynamic analyses were carried out using the computer program Opensees [23].

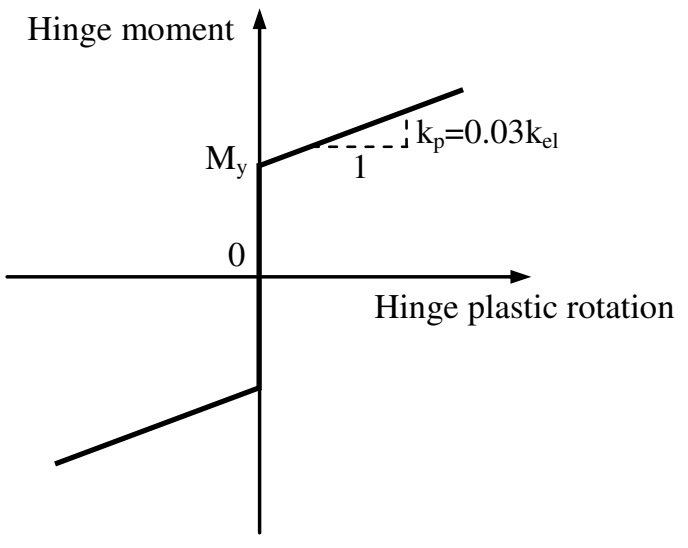

Figure 2. Moment - rotation relationship of a rigid-plastic hinge with $3 \%$ strain hardening ratio.
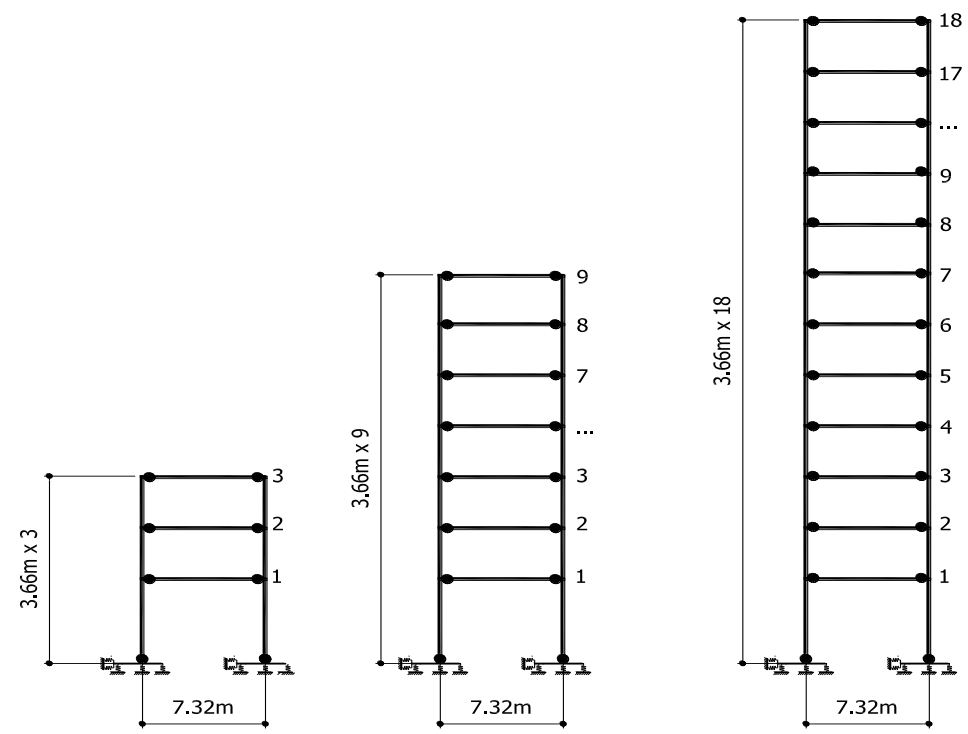

Figure 3. The elevation view of all systems.
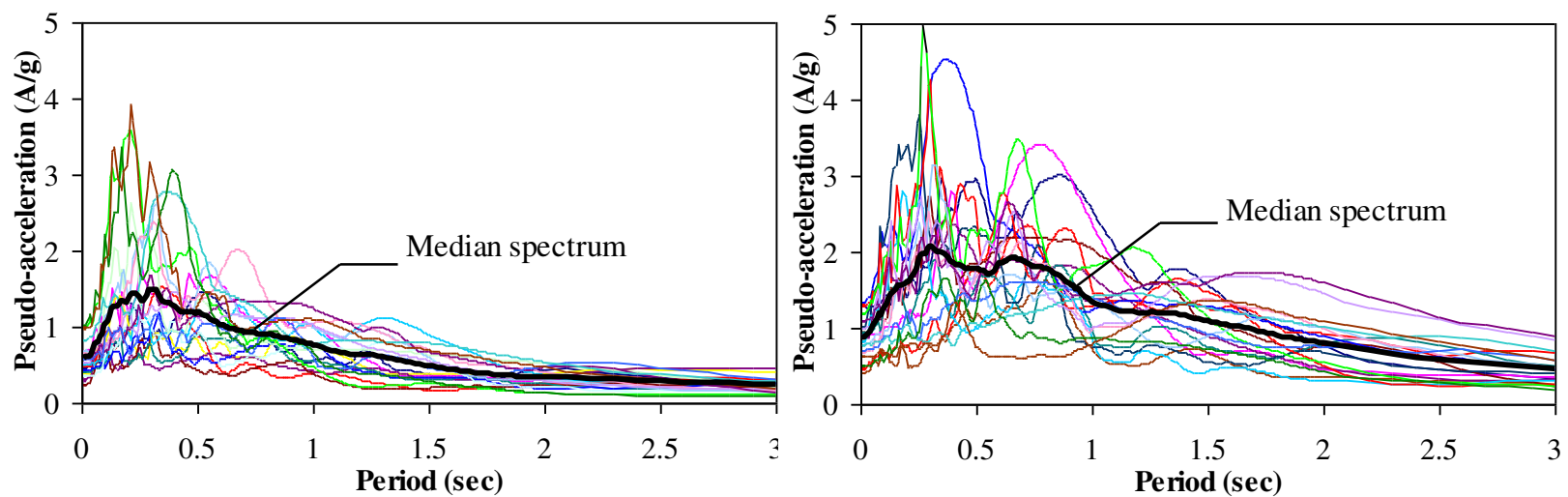

Figure 4. Pseudo-acceleration spectra of (a) LA10/50, and (b) LA2/50 set of ground motions. 
Table 1 . Set of ground motions having $2 \%$ probability of being exceeded in 50 years (LA2/50)

\begin{tabular}{|c|c|c|c|c|c|}
\hline Record & Earthquake/Recording station & $\begin{array}{c}\text { Earthquake } \\
\text { magnitude }\end{array}$ & $\begin{array}{c}\text { Distance } \\
(\mathrm{km})\end{array}$ & $\begin{array}{c}\text { Scaling } \\
\text { factor }\end{array}$ & 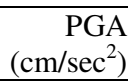 \\
\hline$\overline{\mathrm{LA}} 21$ & 1995 Kobe & 6.9 & 3.4 & 1.15 & 1258 \\
\hline LA22 & 1995 Kobe & 6.9 & 3.4 & 1.15 & 903 \\
\hline LA23 & 1989 Loma Prieta & 7.0 & 3.5 & 0.82 & 410 \\
\hline LA24 & 1989 Loma Prieta & 7.0 & 3.5 & 0.82 & 464 \\
\hline LA25 & 1994 Northridge & 6.7 & 7.5 & 1.29 & 854 \\
\hline LA26 & 1994 Northridge & 6.7 & 7.5 & 1.29 & 925 \\
\hline LA27 & 1994 Northridge & 6.7 & 6.4 & 1.61 & 909 \\
\hline LA28 & 1994 Northridge & 6.7 & 6.4 & 1.61 & 1304 \\
\hline LA29 & 1974 Tabas & 7.4 & 1.2 & 1.08 & 793 \\
\hline LA30 & 1974 Tabas & 7.4 & 1.2 & 1.08 & 973 \\
\hline LA31 & Elysian Park (simulated) & 7.1 & 17.5 & 1.43 & 1271 \\
\hline LA32 & Elysian Park (simulated) & 7.1 & 17.5 & 1.43 & 1164 \\
\hline LA33 & Elysian Park (simulated) & 7.1 & 10.7 & 0.97 & 767 \\
\hline LA34 & Elysian Park (simulated) & 7.1 & 10.7 & 0.97 & 668 \\
\hline LA35 & Elysian Park (simulated) & 7.1 & 11.2 & 1.10 & 973 \\
\hline LA36 & Elysian Park (simulated) & 7.1 & 11.2 & 1.10 & 1079 \\
\hline LA37 & Palos Verdes (simulated) & 7.1 & 1.5 & 0.90 & 698 \\
\hline LA38 & Palos Verdes (simulated) & 7.1 & 1.5 & 0.90 & 761 \\
\hline LA39 & Palos Verdes (simulated) & 7.1 & 1.5 & 0.88 & 491 \\
\hline LA40 & Palos Verdes (simulated) & 7.1 & 1.5 & 0.88 & 613 \\
\hline
\end{tabular}

Table 2. Median ductility factors for building models calculated from NL-RHA estimate of peak roof displacement

\begin{tabular}{lccc}
\hline \multirow{2}{*}{ Set of records } & \multicolumn{3}{c}{ Building model } \\
\cline { 2 - 4 } & 3-story & 9 -story & 18-story \\
\hline LA10/50 & 2.35 & 2.31 & 2.04 \\
LA2/50 & 3.73 & 3.63 & 3.50 \\
\hline
\end{tabular}

In order to consider the influence of soil-structure interaction in this study, a numerical model based on the Beam-on-Nonlinear-Winkler Foundation (BNWF) concept is used to capture the above mentioned foundation behavior (Raychowdhury, P. 2008) [20]. The BNWF model is selected due to its relative simplicity, ease of calibration, and acceptance in engineering practice. The soil-foundation interface is assumed to be an assembly of discrete, nonlinear elements composed of springs, dashpots and gap elements. Inelastic nonlinear springs are used to describe the resistance of soil foundation in horizontal and vertical directions.

The foundation model used in this study is considered as an elastic beam element and is declared with the "elasticBeamColumn" element in the OPENSEES software. Each node of the element has three degrees of freedom representing loads and deformations in horizontal, vertical, rotational angle. This element is supported by separate nonlinear springs. The springs are declared with the element "zeroLength Element". For the interaction problem, Boulanger et al. [24] has proposed a model of QzSimple1, PySimple1 and TzSimple1 material to simulate the response of the soil to the pile during the load bearing process. These materials are attached to the spring element to create a nonlinear behavior of the spring. Raychowdhury (2008) [20] proposed models of QzSimple2, PySimple2, TzSimple2 materials that have been modified from the QzSimple1,
PySimple1, and TzSimple1 material models by the result of experiments in fact. This correction aims to create a soil response that impacts to the foundation structure exactly during the load bearing process. The BNWF model can simulate the behavior of soil-foundation structures through nonlinear behavior of ground (geometrical and material nonlinearities).

\section{GROUND MOTIONS AND RESPONSE STATISTICS}

Two sets of ground motions, referred as LA2/50 and LA10/50, corresponding to $2 \%$ and $10 \%$ probabilities of exceedence in a 50-year period are used in this study. These ground motions were compiled by the SAC Phase II Steel Project for a site in Los Angeles, California (Somerville et al., 1997) [25]. These acceleration time histories were derived from historical recordings or from simulations of physical fault rupture processes. Each set of ground motions consists of 20 records which are the fault-normal and fault-parallel components of 10 recordings. The records in these suites include near-fault and far-fault records. The pseudo-acceleration spectra for the two sets of ground motions are shown in Figure 4 together with the median spectra (black solid lines). Table 1 provides the information of LA2/50 set of records including: recording station, earthquake 
magnitude, distance, scaling factor, and peak ground acceleration (PGA).

The response of each building to each set of the ground motions was determined by nonlinear response history analysis (NL-RHA), and the Adaptive Modal Combination (AMC) procedure. The peak value of interstory drift, $\Delta$, determined by NL-RHA is denoted by $\Delta_{N L-R H A}$, and from AMC by $\Delta_{A M C}$. From these data for each ground motion, a response ratio was determined from the following equation: $\Delta_{A M C}^{*}=\Delta_{A M C} / \Delta_{N L-R H A}$. The median values, $\hat{x}$, defined as the geometric mean, of $n$ observed values $\left(x_{i}\right)$ of $\Delta_{A M C}, \Delta_{N L-R H A}$ and $\Delta_{A M C}^{*}$; and the dispersion measures $\delta$ of $\Delta_{A M C}^{*}$ defined as the standard deviation of logarithm of the $n$ observed values were calculated:

$\hat{x}=\exp \left[\frac{\sum_{i=1}^{n} \ln x_{i}}{n}\right]$

$$
\delta=\sqrt{\frac{\sum_{i=1}^{n}\left(\ln x_{i}-\ln \hat{x}\right)^{2}}{n-1}}
$$

\section{EVALUATION OF ADAPTIVE MODAL COMBINATION PROCEDURE}

The bias and accuracy of the AMC procedure applied to buildings are evaluated by comparing the target roof displacements, peak floor (or roof) displacements and inter-story drifts compared to more accurate results from nonlinear response history analysis (NL-RHA) and results from AMC procedure considered only first mode (AMC- 1st mode).

\section{Target Roof Displacements}

Pushover curves, which show the relationship between the base shear force and the roof displacement, for the 3-, 9-, and 18-story buildings due to the first 'mode' load pattern are plotted in Figure 5.

On each pushover curve, diamond markers show the peak roof displacements of buildings determined by NLRHA of the equivalent single-degree-of-freedom (SDF) system due to 20 records in each set of ground motions. The ductility factors of the first 'mode', defined here as the ratio between median of peak roof displacements

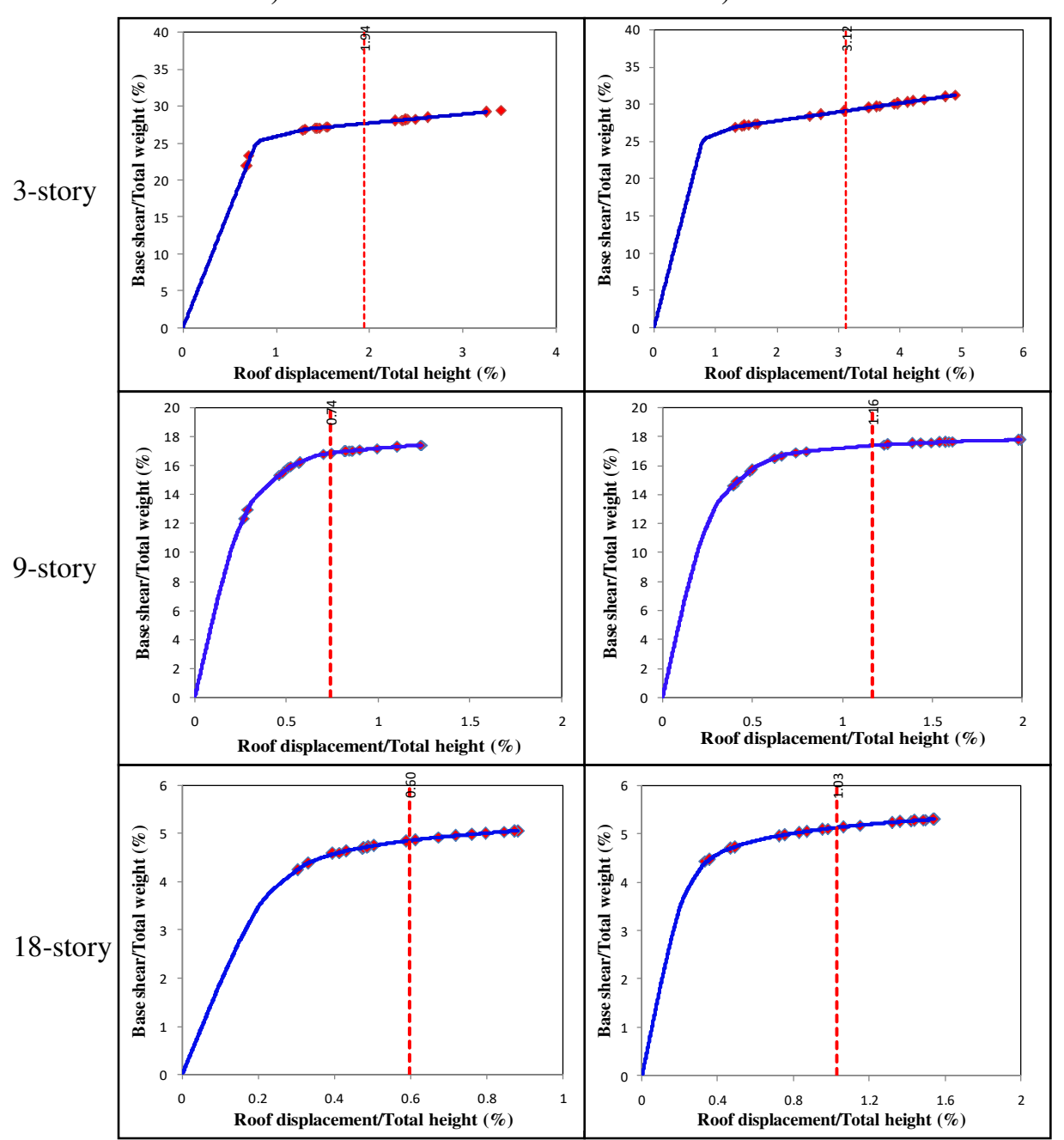

Figure 5. First 'mode' pushover curves of 3-, 9-, and 18-story buildings due to (a) LA10/50 and (b) LA2/50 ground motions. 
determined by NL-RHA and yield roof displacement estimated by first 'mode' load pattern, are about 2.04 to 2.35 for LA10/50 and 3.50 to 3.73 for LA2/50 ground motions, respectively. Table 2 shows the median ductility factors for these buildings calculated from NLRHA estimate. The median ductility factor decreases when the building height increases.

\section{Peak floor/roof displacements}

The responses of studied buildings to the two sets of ground motions were determined by $\mathrm{AMC}-1^{\text {st }}$ mode, AMC procedure and by nonlinear response history analysis (NL-RHA). The AMC was considered as many modes as to include participating mass at least $90 \%$ of total mass. For the structures in this study, the contribution of the first two 'modes' for 3-story building, three 'modes' for 9-story building, and five 'modes' for 18 -story building were considered to estimate the seismic demands. The combined values of floor displacements and story drifts were computed by using SRSS modal combination rule.

The peak floor/roof displacement demands from three methods are compared in Figure 6. These results lead to the following observations for building system. The AMC $-1^{\text {st }}$ mode and AMC can estimate the peak floor displacements reasonably well for 3-story and 9-story buildings with a tendency to slightly overestimate floor/roof displacements for upper stories of 9-story building due to LA2/50 set of ground motions. The contributions of higher 'modes' of AMC procedure to floor displacements are significant for 9-story building due to the two sets of ground motions. The AMC procedure can well predict floor displacements of upper and lower stories of 18-story building compared to NLRHA whereas the AMC- ${ }^{\text {st }}$ mode procedure tends to underestimate peak floor displacements of 18-story building considered in this study.

\section{Story drift demands}

The contributions of higher 'modes' in estimating the story drifts of AMC procedure are more significant, especially in lower and upper stories of tall buildings. Figure 7 shows that the story drift demands of 3-, 9- and 18-story buildings predicted by AMC are able to follow the NL-RHA results whereas the AMC first 'mode' alone is inadequate. With three or five 'modes' included, the story drifts estimated by AMC is generally similar to the results from nonlinear RHA. However, the AMC story drift results including two 'modes' for 3-story are close to $\mathrm{AMC}-1^{\text {st }}$ mode results indicating that the contributions of higher 'modes' are not significant for this building. Both one 'mode' pushover analysis and AMC can estimate the response of structures reasonably well. The AMC and AMC - $1^{\text {st }}$ mode procedures tend to

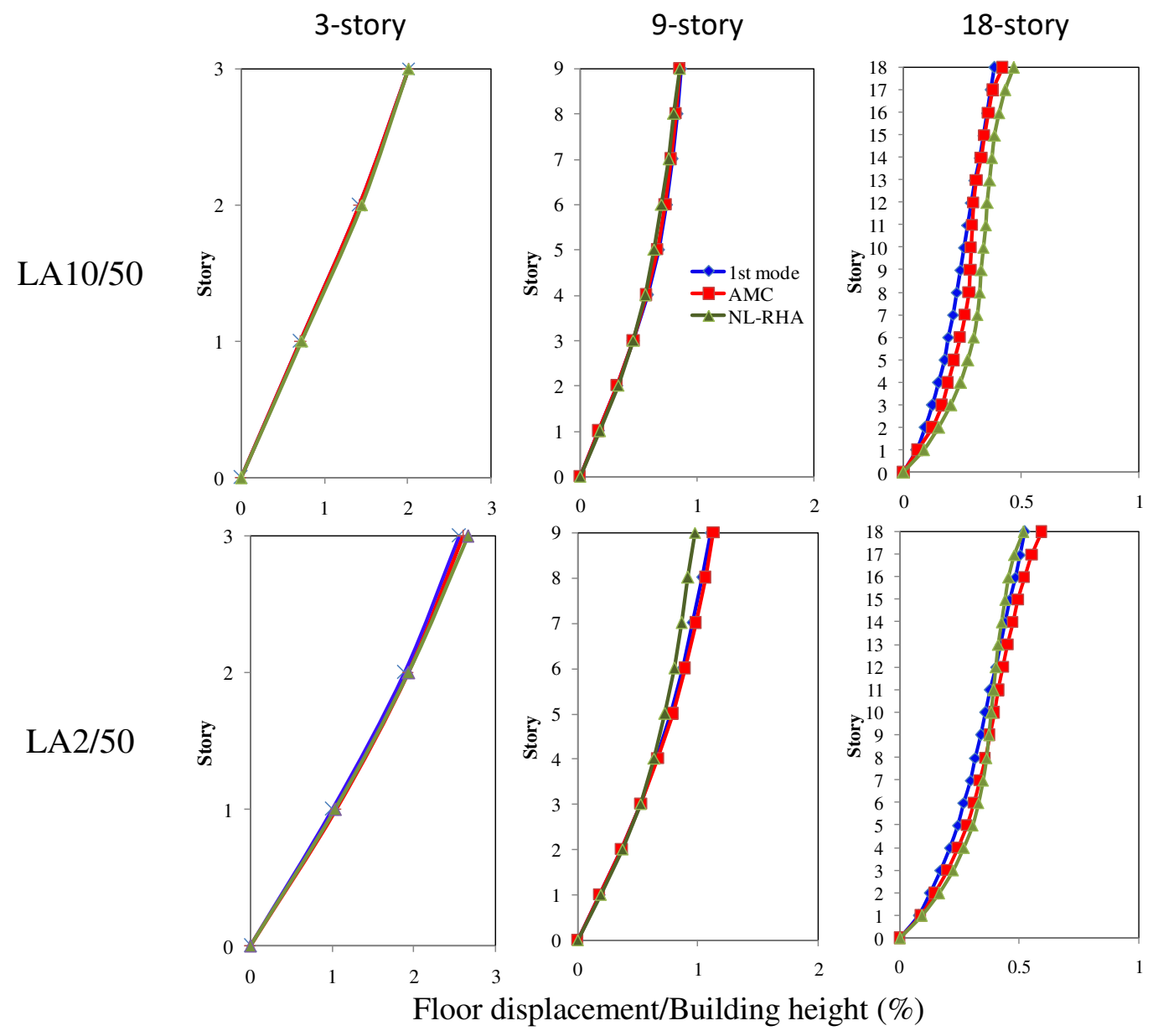

Figure 6. Median floor displacements of 3-, 9-, and 18-story buildings determined by one 'mode' pushover analysis, AMC and NL-RHA due to LA10/50 (first row), and LA2/50 (second row) ground motions. 

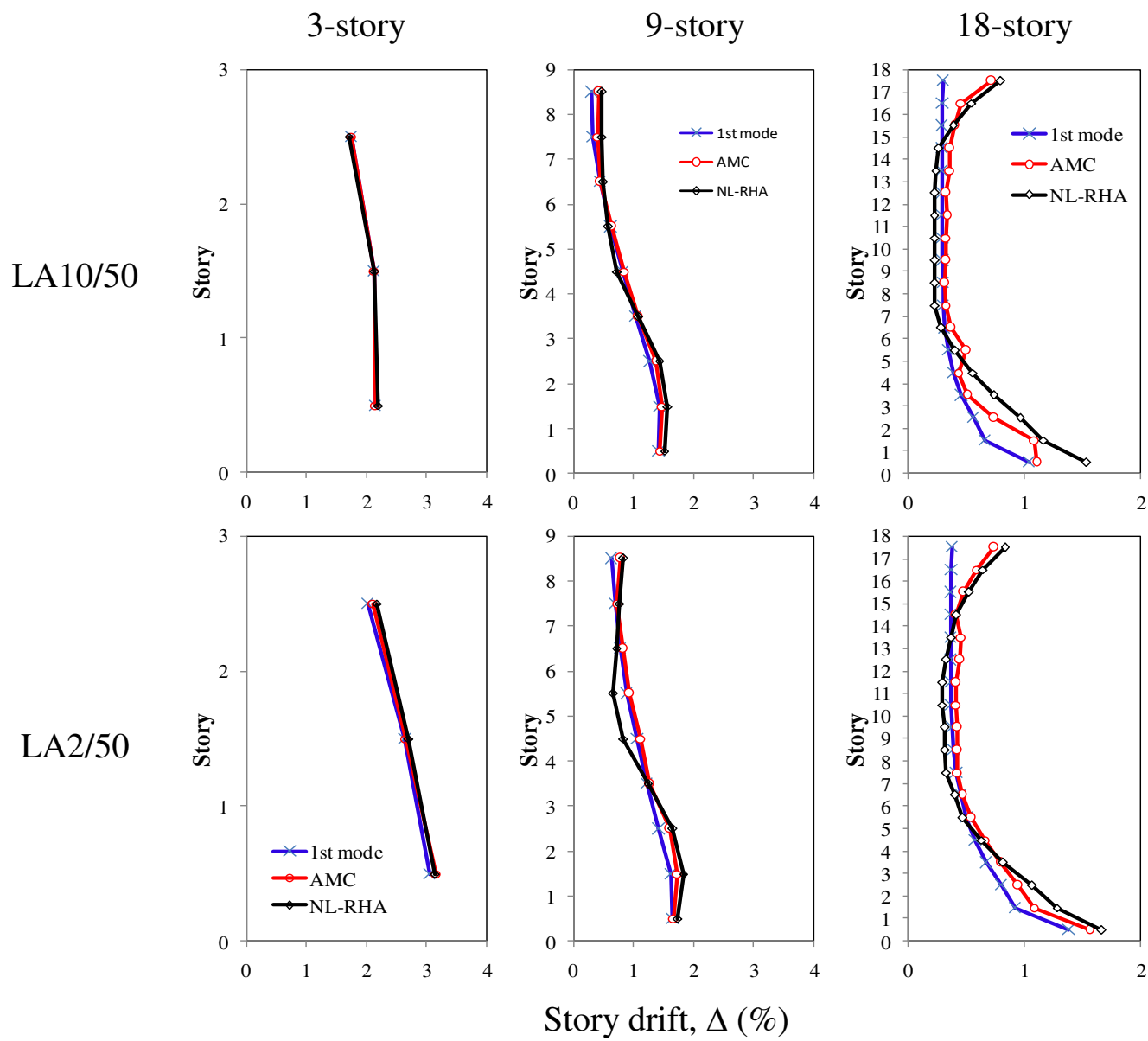

Figure 7. Median story drifts of 3-, 9-, and 18-story buildings determined by AMC- $1^{\text {st }}$ mode, AMC and NL-RHA due to LA10/50 (first row), and LA2/50 (second row) ground motions.

underestimate story drifts in lower and upper stories, and overestimate story drifts in middle stories of 9- and 18story buildings due to the two sets of ground motions.

The bias of AMC nonlinear static procedures in estimating seismic demands tends to increase for stronger excitations and the variation of AMC bias in estimating seismic demands along building height primarily depends on the building height rather than the intensity of ground motions. The bias of AMC and AMC- $1^{\text {st }}$ mode in estimating peak story drifts at an individual story can be as large as $50 \%$ at certain locations for LA10/50 and LA2/50 ground motions.

\section{CONCLUSIONS}

The following conclusions are obtained from the accuracy assessment of Adaptive Modal Combination procedure in estimating seismic demands of buildings considered soil structure interaction using LA10/50 and LA2/50 sets of intense ground motions. These conclusions are based on a comparison of AMC estimates of seismic demands and corresponding values determined by NL-RHA for 3-, 9-, and 18-story buildings which were designed to meet seismic code criteria.

(1) The equivalent bilinear SDF systems of AMC procedure can estimate peak roof displacement quite accurately with bias no larger than $11 \%$ and $15.6 \%$ for
LA10/50 and LA2/50 sets of ground motions, respectively.

(2) The story drift demands predicted by AMC are able to follow the NL-RHA results. However, the higher 'modes' contributions of this procedure in response of 3 story building are generally not significant, so the first 'mode' alone may be adequate.

(3) The bias and dispersion of AMC procedure in estimating seismic demands tends to increase for taller buildings and stronger excitations. The height-wise variation of bias primarily depends on structural properties, e.g., building height, rather than the intensity of ground motions.

(4) The bias of AMC and AMC-1st mode in estimating peak story drifts at an individual story can be as large as $50 \%$ at certain locations for LA10/50 and LA2/50 ground motions.

\section{ACKNOWLEDGEMENTS}

The authors would like to acknowledge the financial support provided by Japan International Cooperation Agency (JICA) through the ASEAN University Network / Southeast Asia Engineering Education Development Network (AUN/SEED-Net) program. 


\section{REFERENCES}

[1] ATC, "Seismic evaluation and retrofit of concrete buildings," Appl. Technol. Counc., vol. 1, 1996.

[2] FEMA 2000, "Prestandard and Commentary for the Seismic Rehabilitation of Buildings," 2000

[3] Applied Technology Council (ATC), 2005. Improvement of inelastic seismic analysis procedures. Report FEMA-440. Washington, D.C: Federal Emergency Management Agency.

[4] Chopra AK, Goel RK, "A modal pushover analysis procedure for estimating seismic demands for buildings," Earthquake Engineering and Structural Dynamics, 31(3): 561-582, 2002.

[5] Chintanapakdee C, Chopra A.K., "Evaluation of modal pushover analysis using generic frames," Earthquake Engineering and Structural Dynamics, 32(3): 417-442, 2003.

[6] Chopra AK, Chintanapakdee C., "Evaluation of modal and FEMA pushover analyses: vertically "regular" and irregular generic frames," Earthquake Spectra, 20(1): 255-271, 2004.

[7] Chopra AK, Goel RK, Chintanapakdee C., "Evaluation of a modified MPA procedure assuming higher modes as elastic to estimate seismic demands," Earthquake Spectra, 20(3): 757-778, 2004.

[8] Nguyen, A.H., Chintanapakdee, C., and Hayashikawa, T., "Assessment of current nonlinear static procedures for seismic evaluation of BRBF buildings," Journal of Constructional Steel Research, 66(8-9): 1118-1127, 2010.

[9] Chopra, A.K. and Goel, R.K., "Evaluation of NSP to estimate seismic deformation: SDF system. Journal of structure engineering," ASCE 126(4): 482-490, 2000.

[10] Akkar, S., and Metin, A., "Assessment of improved nonlinear static procedures in FEMA-440," Journal of structural engineering, ASCE 133(9): 1237-1246, 2007.

[11] Freeman, S.A., Nicoletti, J.P., and Tyrell, J.V., "Evaluations of existing buildings for seismic risk - A case syudy of Puget Sound Naval Shipyard, Bremerton, Washington," Proceedings of 1st U.S. National Conference on Earthquake Engineering, EERI, Berkeley, 113-122, 1975.

[12] Freeman, S.A., "Prediction of response of concrete buildings to serve earthquake motion," Publication SP-55, American Concrete Institute, Detroit, MI, 589606, 1978.
[13] Chopra, A.K and Goel, R.K., "Capacity-demand-diagram methods based on inelastic design spectrum," Earthquake spectra 15(4): 637-656, $1999 \mathrm{~b}$.

[14] Chopra, A.K., Goel, R.K., and Chintanapakdee, C., "Statistics of SDF-system estimate of roof displacement for pushover analysis of buildings," PEER report no. 2001/16. Pacific earthquake, Engineering research center, University of California, Berkeley, Calif, 2001.

[15] Chopra, A.K., Goel, R.K., and Chintanapakdee, C., "Statistics of single-degreeof-freedom estimate of displacement for pushover analysis of buildings," Journal of structural engineering, ASCE 129(4): 459-469, 2003.

[16] Fajfar, P., and Fischinger, M., "N2 - A method for nonlinear seismic analysis of regular buildings," Proceeding of the ninth world conference on earthquake engineering, TokyoKyoto, Japan, 5: 111-116, 1989.

[17] Bracci, J.M., Kunnath, S.K., and Reinhorn, A.M., "Seismic performance and retrofit evaluation for reinforced concrete structures," Journal of structural engineering, ASCE 123(1) 3-10, 1997.

[18] Gupta, B. and Kunnath, S.K., "Adaptive spectra-based pushover procedure for seismic evaluation of structures," Earthquake spectra 16(2): 367-391, 2000.

[19] Kalkan E, Kunnath S.K., "Adaptive modal combination procedure for nonlinear static analysis of building structures," Structural Engineering, 132(11): 1721-1731, 2006.

[20] Raychowdhury P., "Nonlinear Winkler-based shallow foundation model for performance assessment of seismically loaded structures", $\mathrm{PhD}$. dissertation of University Of California, San Diego, 2008.

[21] Goel, R. K., \& Chopra, A. K., "Period formulas for moment-resisting frame buildings". Journal of Structural Engineering, 123(11), 1454-1461, 1997.

[22] Sabelli R, Mahin SA, Chang C, "Seismic demands on steel braced frame buildings with buckling restrained braces," Engineering Structures, 25(5): 655-666, 2003.

[23] OpenSees, "Open System for Earthquake Engineering Simulation:OpenSees." Pacific Earthquake Engineering Research Center (PEER), University of California, Berkeley. URL: http://opensees.berkeley.edu, 2008.

[24] Boulanger, R. W., Curras, C. J., Kutter, B. L., Wilson, D. W., and Abghari, A, "Seismic soil-pile-structure interaction experiments and analyses," Journal of Geotechnical and Geoenvironmental Engineering, 125(9), 750-759, 1999.

[25] Somerville P, Smith N, Punyamurthula S, Sun J., "Development of ground motion time histories for phase 2 of the FEMA/SAC steel project," Report no. SAC/BD97/04, SAC Joint Venture, Sacramento, California; 1997. 